\title{
Hyperglycemia Induced by Glucokinase Deficiency Accelerates Atherosclerosis Development and Impairs Lesion Regression in Combined Heterozygous Glucokinase and the Apolipoprotein E-Knockout Mice
}

\author{
Damilola D. Adingupu, ${ }^{1}$ Suvi E. Heinonen, ${ }^{1}$ Anne-Christine Andréasson, ${ }^{1}$ \\ Mikael Brusberg, ${ }^{1}$ Andrea Ahnmark, ${ }^{1}$ Margareta Behrendt, ${ }^{1}$ \\ Brendan Leighton, ${ }^{2}$ and Ann-Cathrine Jönsson-Rylander ${ }^{1}$ \\ ${ }^{1}$ CVMD iMED, AstraZeneca R\&D, Gothenburg, Sweden \\ ${ }^{2}$ The Research Network, Sandwich, UK
}

Correspondence should be addressed to Ann-Cathrine Jönsson-Rylander; ann-cathrine.jonsson-rylander@astrazeneca.com

Received 6 May 2016; Accepted 8 August 2016

Academic Editor: Bernard Portha

Copyright (C) 2016 Damilola D. Adingupu et al. This is an open access article distributed under the Creative Commons Attribution License, which permits unrestricted use, distribution, and reproduction in any medium, provided the original work is properly cited.

\begin{abstract}
Aim. Models combining diabetes and atherosclerosis are important in evaluating the cardiovascular (CV) effects and safety of antidiabetes drugs in the development of treatments targeting CV complications. Our aim was to evaluate if crossing the heterozygous glucokinase knockout mouse $\left(\mathrm{GK}^{+/-}\right)$and hyperlipidemic mouse deficient in apolipoprotein $\mathrm{E}\left(\mathrm{ApoE}^{-/-}\right)$will generate a disease model exhibiting a diabetic and macrovascular phenotype. Methods. The effects of defective glucokinase on the glucose metabolism and on the progression and regression of atherosclerosis on high-fat diets were studied in both genders of $\mathrm{GK}^{+/-} \mathrm{ApoE}^{-/-}$and $\mathrm{ApoE}^{-/-}$mice. Coronary vascular function of the female $\mathrm{GK}^{+/-} \mathrm{ApoE}^{-/-}$and $\mathrm{ApoE} \mathrm{E}^{-/-}$mice was also investigated. Results. $\mathrm{GK}^{+/-} \mathrm{ApoE}^{-/-}$mice show a stable hyperglycemia which was increased on Western diet. In oral glucose tolerance test, $\mathrm{GK}^{+/-} \mathrm{ApoE}^{-/-}$mice showed significant glucose intolerance and impaired glucose-stimulated insulin secretion. Plasma lipids were comparable with $\mathrm{ApoE}^{-/-}$mice; nevertheless the $\mathrm{GK}^{+/-} \mathrm{ApoE}^{-/-}$mice showed slightly increased atherosclerosis development. Conclusions. The $\mathrm{GK}^{+/-} \mathrm{ApoE}^{-/-}$mice showed a stable and reproducible hyperglycemia, accelerated atherosclerotic lesion progression, and no lesion regression after lipid lowering. This novel model provides a promising tool for drug discovery, enabling the evaluation of compound effects against both diabetic and cardiovascular endpoints simultaneously in one animal model.
\end{abstract}

\section{Introduction}

Diabetes is rising globally, with the prevalence of type 2 diabetes (T2D) especially starting to reach epidemic proportions [1]. The metabolic abnormalities that characterize T2D have long been shown to induce molecular mechanisms that contribute to accelerated atherosclerosis progression [2]. Moreover, individuals with T2D have an increased risk of developing cardiovascular diseases and higher cardiovascular mortality rates compared with individuals without T2D [3]. Despite the advances in antidiabetic treatments, effective glycemic control is not always achieved in patients and cardiovascular benefits of treatments are not always demonstrated. To address the need for antidiabetic treatments that are effective against both underlying pathology in T2D and associated cardiovascular complications, studies testing novel drug candidates require a predictive and translational animal model which closely represents the disease pathology.

In the pancreas, glucokinase (GK) determines the rate of glucose-stimulated insulin secretion (GSIS), whereas in the liver the rates of glucose utilization and glycogen synthesis are regulated by the GK activity. Thus, GK plays a critical role in 
the regulation of blood glucose by acting as the glucose sensor in both pancreas and liver $[4,5]$. In humans, heterozygous point mutations in the glucokinase (GK) gene result in reduced enzymatic activity and decreased insulin secretion, causing maturity onset diabetes of the young (MODY) with early-onset and persistent hyperglycemia [6]. Reduced GK activity has been suggested to contribute to impaired insulin secretion, as well as to the abnormalities in hepatic glucose balance in humans with T2D [7-10].

Animal models of GK depletion have been developed in the past, but with limited success. $\beta$-cell specific GK knockout is lethal; therefore, a nonleptin dependent global heterozygous depletion of glucokinase gene was generated at AstraZeneca [11]: a model that has proven responsive to standard-of-care antidiabetic agents like metformin, sitagliptin, exendin, glipizide, and GK activators [12]. This heterozygous glucokinase knockout $\left(\mathrm{GK}^{+/-}\right)$mouse model has a global disruption of one allele for the GK gene, causing decreased GK activity in both pancreas and liver and leading to reduced insulin secretion and elevated blood glucose levels [11]. The $\mathrm{GK}^{+/-}$mice were recently shown to back-translate the effects of various standard-of-care antidiabetic agents with different mechanism of actions at clinically translatable free-drug exposure levels [13]. Additionally, these authors also showed that, due to the stability of its diabetic phenotype, the $\mathrm{GK}^{+/-}$mouse can be used for long-term safety studies of novel glucose-lowering agents [13]. These characteristics make the $\mathrm{GK}^{+/-}$mouse an attractive model to be used in drug development programs for new antidiabetic agents.

In order to develop a diabetic atherosclerotic mouse model with characteristics that closely resemble the human T2D driven cardiovascular disease, we cross-bred the abovementioned mouse model $\left(\mathrm{GK}^{+/-}\right)$into an apolipoprotein $\mathrm{E}\left(\mathrm{ApoE}^{-/-}\right)$deficient background, to derive a heterozygous glucokinase and apolipoprotein E-knockout mouse $\left(\mathrm{GK}^{+/-} \mathrm{ApoE}^{-/-}\right)$. In this study, we describe the generation of the $\mathrm{GK}^{+/-} \mathrm{ApoE}^{-/-}$mice and characterize their phenotypes, diabetic as well as lipid. In addition, the progression and regression of the atherosclerotic disease process were compared with nondiabetic $\mathrm{ApoE}^{-/-}$mice. The coronary vascular function of the female $\mathrm{GK}^{+/-} \mathrm{ApoE}^{-/-}$mice was evaluated. The main goal was to accomplish a model that would be suitable for the evaluation of combined T2D and cardiovascular endpoints in drug development.

\section{Materials and Methods}

2.1. Animals. Animal care and experiments conform to the Directive 2010/63/EU of the European Parliament on the guidelines for the protection of animals used for scientific purposes and were approved by The Regional Animal Ethics Committee for Experimental Animals, University of Gothenburg. Studies are reported in accordance with the ARRIVE guidelines for reporting experiments involving animals [14].

Mice deficient in apolipoprotein $\mathrm{E}\left(\mathrm{ApoE}^{-/-}\right)$on the C57BL/6N background (AstraZeneca, Sweden) were crossed with C57BL/6J mice with a global deletion in one glucokinase allele $\left(\mathrm{GK}^{+/-}\right)$. Detailed description of the generation of the $\mathrm{GK}^{+-}$was given in a previously published article [11]. $\mathrm{GK}^{+/-} \mathrm{ApoE}^{-/-}$colony was maintained by backcrossing to $\mathrm{ApoE}^{-/-}$mice and thus the $\mathrm{GK}^{+/-} \mathrm{ApoE}^{-/-}$mice gradually acquired a complete C57BL/6N genetic background. ApoE deficient $\left(\mathrm{ApoE}^{-/-}\right)$littermates with functional GK were used as controls in all experiments.

Male mice were housed individually and female mice in groups of five in rooms with regulated temperature, humidity, and a 12 hours' light-dark cycle (lights off 19:00). They had free access to normal Chow diet (R3; Lactamin AB, Kimstad, Sweden) and water, unless stated otherwise in substudies. Body weights were monitored weekly during the studies. Mice were sacrificed during anesthesia with 5\% isoflurane, following blood withdrawal from left ventricle.

2.2. Characterization of Diabetic Phenotype. The effect of high-fat Western diet (WD) (R638; Lactamin AB, Kimstad, Sweden) on the diabetic phenotype of the $\mathrm{GK}^{+/-} \mathrm{ApoE}^{-/-}$ mice was investigated in 10 male and 10 female $\mathrm{GK}^{+/-} \mathrm{ApoE}^{-/-}$mice compared with the sex matched wildtype Apo: $\mathrm{E}^{-/-}$mice $(n=20)$. Basal levels of blood glucose and insulin were measured in the mice which were fed normal Chow diet before starting the WD (Figure 1(a)). Blood glucose was measured after 4-hour fasting at 4, 8, and 14 and 21 weeks after starting WD, using a hand-held Accu-Chek glucose monitor glucometer (Accu-Chek, Roche Diagnostics, Mannheim, Germany) in the awake mice. At the same time points, a blood sample of $\sim 20 \mu \mathrm{L}$ was collected for insulin measurement.

Oral glucose tolerance and insulin sensitivity were examined by performing a tolerance test in the $\mathrm{GK}^{+/-} \mathrm{ApoE}^{-/-}$ mice and the $\mathrm{ApoE}^{-/-}$mice for comparison after 14 weeks on WD. Oral glucose tolerance tests (OGTT) were performed at 13:00 hour after 4-hour fasting by an oral administration of glucose $(2 \mathrm{~g} / \mathrm{kg})$ and $15-20 \mu \mathrm{L}$ blood was drawn from the tail vein at 0 (right before the dosing), 15, 30,60, and $120 \mathrm{~min}$ for the measurement of glucose $(2 \mu \mathrm{L}$, Accu-Chek, Roche Diagnostics, Mannheim, Germany) and insulin $(2 \times 5 \mu \mathrm{L}$, Ultra-Sensitive Mouse Insulin ELISA Kit, Crystal Chemical, Downers Grove, IL) levels. Area under the curve (AUC) values were calculated for glucose and insulin as total area under the curve and corrected for differences in baseline values.

Plasma insulin levels were measured with a radioimmunoassay (SRI-13K, Millipore Corporation, USA) on a 1470 Automatic Gamma Counter (PerkinElmer, USA). Whole blood insulin was measured with an ELISA kit (UltraSensitive Mouse Insulin ELISA Kit; Crystal Chem, Downers Grove, IL).

2.3. Atherosclerosis Progression and Regression. To investigate atherosclerosis progression on different high-fat diets, $\mathrm{GK}^{+/-} \mathrm{ApoE}^{-/-}$mice and $\mathrm{ApoE}^{-/-}$males and females ( $n=$ 10/gender/genotype) were switched from normal Chow diet to Lard diet $(821424 ; 21 \%$ fat from pork lard, $0.15 \%$ cholesterol; Special Diets Services, Essex, UK) for 14 weeks, or Western 


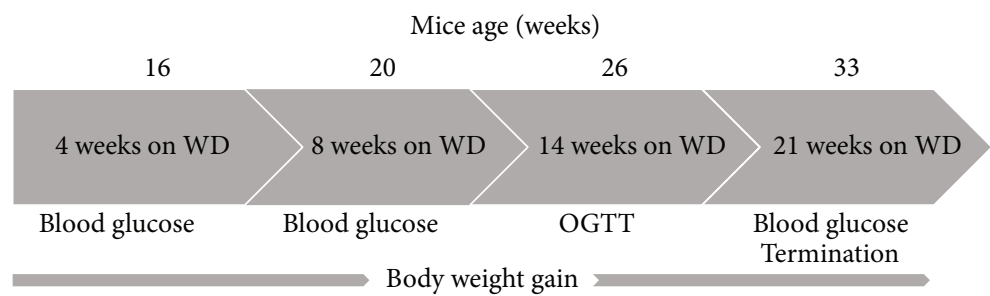

(a)

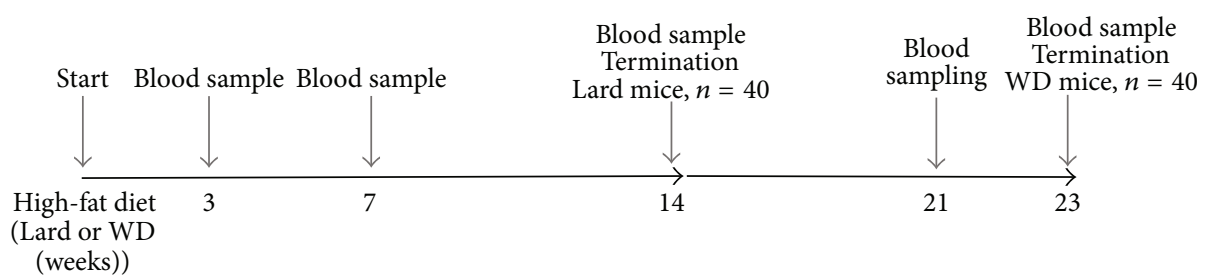

(b)

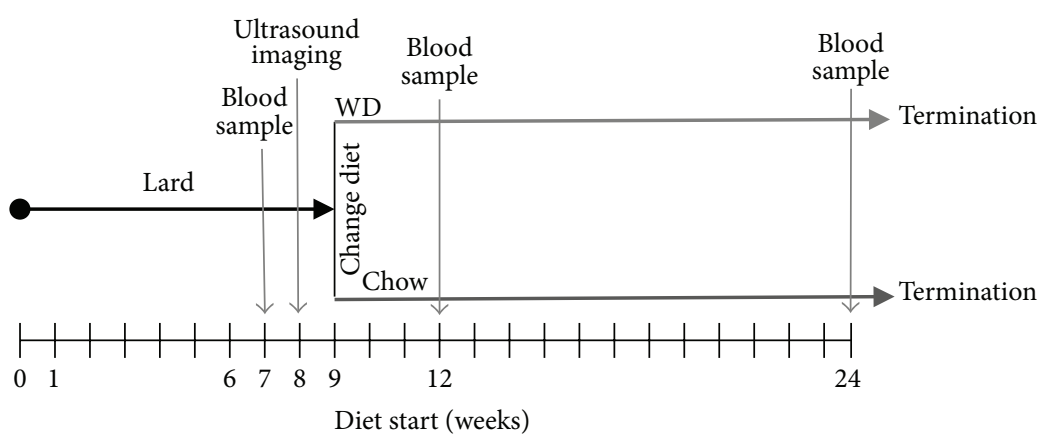

(c)

FIGURE 1: Study design for the characterization of the diabetic phenotype of the $\mathrm{GK}^{+/-} \mathrm{ApoE}^{-/-}$and the ApoE ${ }^{-/-}$mice on Western diet (WD) (a), study design for the atheroprogression study (b), and atheroregression study (c).

diet (WD) (R638; 21\% fat/cocoa butter, $0.15 \%$ cholesterol; Lantmännen, Kimstad, Sweden) for 23 weeks (Figure 1(b)). This aimed to accelerate the hyperlipidemia progress and pathological cardiovascular phenotype. Cholesterol was measured at 3 and 7 weeks after diet commenced and at termination (14 weeks in the Lard diet group and 23 weeks in the WD group).

In addition, to investigate atherosclerosis regression, 18week-old $\mathrm{GK}^{+/-} \mathrm{ApoE}^{-/-}$and $\mathrm{ApoE}^{-/-}$males and females ( $n=10$ /gender/genotype) were first transferred from Chow to Lard diet $(821424 ; 21 \%$ fat from pork lard, $0.15 \%$ cholesterol; Special Diets Services, Essex, UK) for 9 weeks to establish atherosclerotic lesions and then split into two groups (1) Chow diet and (2) WD for 14 weeks (Figure 1(c)). Animals were allocated to the different diet intervention groups by randomization based on plaque size in the brachiocephalic artery (BCA) measured by noninvasive ultrasound imaging.

2.4. Analyses of Plasma Lipid Levels. Blood samples during the study were drawn from the saphenous vein and by cardiac puncture at termination, placed into MiniCollect K3E EDTA tubes (Greiner Bio-One $\mathrm{GmbH}$, Kremsmünster, Austria) on ice, and centrifuged $\left(2800 \mathrm{rpm}, 4^{\circ} \mathrm{C}, 10 \mathrm{~min}\right)$. Plasma was stored at $-80^{\circ} \mathrm{C}$ until analysis. Plasma lipid concentrations were measured using enzymatic colorimetric methods (total cholesterol: kit number A11A01634, Horiba ABX, France; triglycerides: kit number 12146029, Roche Diagnostics GmbH, Germany; nonesterified fatty acids: NEFA-HR (2) assay, 434-91795 and 436-91995, Wako Chemicals GmbH, Germany).

2.5. Histological Analyses. Heart, BCA, and thoracic aorta were dissected out and fixed in 4\% phosphate-buffered formaldehyde (number 02176, HistoLab Products, Gothenburg, Sweden). Thoracic aortas were cleaned from the adventitia and opened longitudinally and macroscopic lesions were quantified en face and photographed and images were imported into BioPix IQ 2.1.8 image analysis system (BioPix $\mathrm{AB}$, Gothenburg, Sweden) which was used for quantification. Samples of aortic sinus, ascending aorta, and BCA were embedded in paraffin and serial $4 \mu \mathrm{m}$ sections were cut (Histocenter, Gothenburg, Sweden). Sections were either stained with conventional stains (hematoxylin-eosin, Miller's elastin, or Picrosirius red; Histocenter, Gothenburg, Sweden) or immunostained for smooth muscle cells ( $\alpha$-actin, 1:100, clone 1A4, Dako, M0851) or macrophages (MAC-2, 
1:10000, clone M3/38, CL8942AP, Cedarlane) using DAB (BC-BDB2004, Biocare) as the chromogen. Immunostaining was performed as single or dual stain using an automated stainer (Intellipath, Biocare). Slides were then scanned in an automated slide scanner (Mirax Scan, Zeiss) and images were analyzed with BioPix IQ 2.1.8 image analysis system (BioPix AB, Gothenburg, Sweden). Plaque area and area of positive staining were measured. Positive staining was related to plaque area. All histological procedures and analyses were performed in a blinded fashion.

2.6. Coronary Flow Velocity Reserve (CFVR) Measured Using Ultrasound Imaging. Transthoracic echocardiography was performed using noninvasive high-frequency ultrasound imaging in the atherosclerosis regression study on 18-weekold $\mathrm{GK}^{+/-} \mathrm{ApoE}^{-/-}$and ApoE ${ }^{-/-}$female mice to characterize coronary vascular function. All mice were anesthetized with Isoba ${ }^{\circledR}$ vet isoflurane (Schering-Plough Ltd., England) in a closed chamber with $3 \%$ isoflurane in oxygen for 2 to 5 minutes until immobile and $1.0-1.5 \%$ isoflurane in oxygen during the examination. Each mouse was placed supine on a heated procedure board with isoflurane initially at $1.5 \%$ supplied by a nose cone connected to the anesthesia vaporizer. Chest hair was removed with chemical cream (Veet, Reckitt Benckiser, UK). Imaging was done with a highresolution ultrasound scanner (Vevo 770, Visualsonics Inc., Toronto, Canada) using a $40 \mathrm{MHz}$ mechanical transducer with a focal depth of $6 \mathrm{~mm}$. Isoflurane was reduced to $1 \%$ to lower coronary flow to a baseline level and velocity profile in the left coronary artery was measured in a modified long-axis view, recorded with a pulsed-wave Doppler for 3 minutes to ensure stable signal was achieved, after which signals were collected and stored. Isoflurane level was then increased to $2.5 \%$ to increase the coronary flow, and velocity profile was monitored for up to 4 minutes during which time signals were stored for offline analysis of maximum hyperemic response. Isoflurane was reduced back to $1 \%$, and mice were allowed to stabilize. Detailed protocol using isoflurane to induce hyperemia has been described elsewhere [15]. Plaque size and CFVR analysis were measured offline (Vevo770 software, Visualsonics Inc., Toronto, Canada) in a blinded fashion.

CFVR was calculated as the ratio of peak diastolic flow velocities at baseline obtained using $1 \%$ isoflurane and during hyperemia obtained using $2.5 \%$ isoflurane (CFVR = hyperemic coronary flow velocity/basal coronary flow velocity).

2.7. Statistical Analyses. To detect a $20 \%$ difference in blood glucose at $p<0.05$ with $80 \%$ power, we would require group size of $n=8$. However, since detecting differences in atherosclerosis requires bigger group sizes due to expected larger variation, group sizes were $n=10$. Numerical values for each measurement are shown as mean \pm SEM. Statistical significance was evaluated using 1-sided (blood glucose, plaque size, en face lesion area) or 2-sided (body weight, insulin, cholesterol, and triglyceride (TG)) Student's $t$-test. Significant statistical difference was considered at $p<$ 0.05 . For the OGTT, ANOVA of repeated measures and Tukey's correction for multiple comparisons were used. All

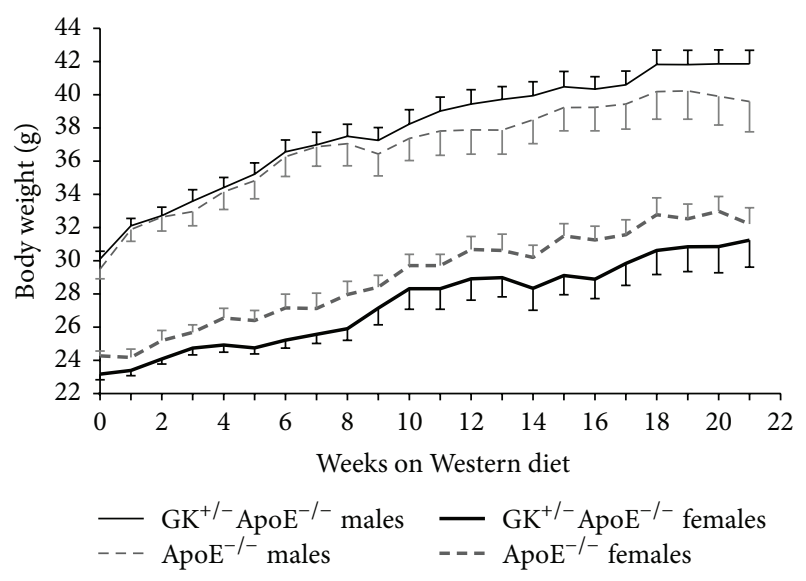

Figure 2: Body weight development of the $\mathrm{GK}^{+/-} \mathrm{ApoE}^{-/-}$mice compared with the ApoE ${ }^{-/-}$mice on $\mathrm{WD} . \mathrm{GK}^{+/-} \mathrm{ApoE}^{-/-}$males have a higher body weight compared with the $\mathrm{ApoE}^{-/-}$males after 21 weeks on WD. ApoE ${ }^{-1-}$ females have a higher body weight from baseline Chow diet and maintained the weight difference on WD compared with $\mathrm{GK}^{+/-} \mathrm{ApoE}^{-/-}$female mice. Values are presented as means and standard error of mean (SEM).

statistical analyses were performed using GraphPad Prism version 6.01 (GraphPad Prism version 6.01 for Windows, GraphPad Software, La Jolla, California, USA).

\section{Results}

Body weight increased in both genotypes with age reflecting the growth of the animals. There were gender differences in the genotypes, where $\mathrm{GK}^{+/-} \mathrm{ApoE}^{-/-}$males have a higher body weight compared with the ApoE ${ }^{-/-}$males after 21 weeks on WD. Conversely, ApoE ${ }^{-/-}$females have a higher body weight from baseline on Chow diet and maintained the weight difference on WD compared with $\mathrm{GK}^{+/-} \mathrm{ApoE}^{-/-}$ female mice (Figure 2).

\subsection{Progression of Diabetes}

3.1.1. Characterization of Diabetic Phenotype. On Chow diet, the $\mathrm{GK}^{+/-} \mathrm{ApoE}^{-/-}$mice displayed significantly higher fasting blood glucose levels $(15.2 \pm 0.6 \mathrm{mmol} / \mathrm{L}$ in males and $12.2 \pm$ $0.6 \mathrm{mmol} / \mathrm{L}$ in females), compared to the normoglycemic ApoE $^{-/-}$controls $(8.3 \pm 0.3 \mathrm{mmol} / \mathrm{L}$ and $8.1 \pm 0.4 \mathrm{mmol} / \mathrm{L}$ in males and females, resp.) (Figure 3 ). When challenged with $\mathrm{WD}$, the glucose levels increased steadily to a $30 \%$ higher level in the $\mathrm{GK}^{+/-} \mathrm{ApoE}^{-/-}$mice $(19.8 \pm 0.4 \mathrm{mmol} / \mathrm{L}, p<0.0001$, in males and $15.9 \pm 0.6 \mathrm{mmol} / \mathrm{L}, p=0.0001$, in females). In $\mathrm{ApoE}^{-/-}$controls a significant $18 \%$ increase was seen in male mice $(9.8 \pm 0.6 \mathrm{mmol} / \mathrm{L}, p<0.05)$, whereas in females the change was smaller and not statistically significant (15\%, 9.3 \pm $0.5 \mathrm{mmol} / \mathrm{L}, p=0.1266)$.

In an oral glucose tolerance test performed after 14 weeks on WD (Figure 4), $\mathrm{GK}^{+/-} \mathrm{ApoE}^{-/-}$mice showed significant glucose intolerance with 2.3-fold increased $\mathrm{AUC}_{\text {glucose }}$ (Figure 4(b)) and impaired GSIS with $\mathrm{AUC}_{\text {insulin }}$ reduced by 


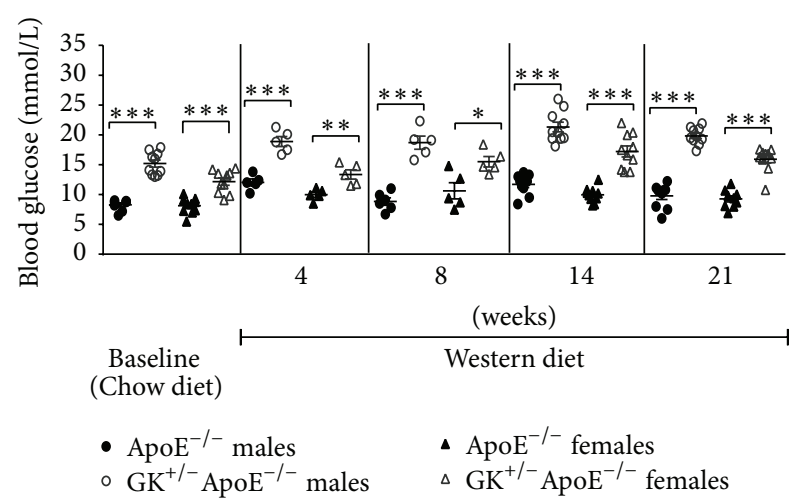

FIgUre 3: Fasting blood glucose is higher in $\mathrm{GK}^{+/-} \mathrm{ApoE}^{-/-}$mice on normal Chow diet and WD at 4, 8, 14, and 21 weeks compared with $\mathrm{ApoE}^{-/-}$mice. Values are presented as individual data points and means. Statistical analysis was performed using $t$-test and a $p$ value of less than 0.05 was considered significant. ${ }^{*} p<0.05,{ }^{* *} p<0.005$, and ${ }^{* * *} p<0.0001$.

$49 \%$ and $27 \%$ (in males and females, resp.) compared to $\mathrm{ApoE}^{-/-}$mice (Figure 4(d)). Defective GSIS was reflected also in basal insulin values, which in general tended to be lower in the $\mathrm{GK}^{+/-} \mathrm{ApoE}^{-/-}$than $\mathrm{ApoE}^{-/-}$mice (Figure 4(c)).

3.1.2. Atheroprogression and Atheroregression Studies. In the atheroprogression and atheroregression studies, hyperglycemia was very stable and more profound in $\mathrm{GK}^{+/-} \mathrm{ApoE}^{-/-}$ mice compared to ApoE mice (data not presented).

\subsection{Lipids}

3.2.1. Atheroprogression Study. Reduction in the GK function did not affect total plasma cholesterol or triglyceride levels (Table 1). In general, cholesterol levels were higher on Lard diet compared with $\mathrm{WD}$ in both genotypes already after 3 weeks. $\mathrm{GK}^{+/-} \mathrm{ApoE}^{-/-}$male mice have a trend for lower cholesterol from study start and show a declining tendency with time. The triglyceride levels were stable in $\mathrm{GK}^{+/-} \mathrm{ApoE}^{-/-}$ mice despite different diets, and there was a trend for lower values in $\mathrm{GK}^{+/-} \mathrm{ApoE}^{-/-}$mice compared to $\mathrm{ApoE}^{-/-}$mice (Table 1).

3.2.2. Atheroregression Study. Priming with Lard diet for 9 weeks in the atherosclerosis regression study induced a 3fold increase in total cholesterol and these levels remained the same after changing to WD with a similar cholesterol content $(0.15 \%)$. On the contrary, after switching from Lard to Chow diet, the total cholesterol levels decreased significantly (43$55 \%)$ in all groups.

\subsection{Atherosclerosis}

3.3.1. Atheroprogression. On $\mathrm{WD}$, in the BCA the female $\mathrm{GK}^{+/-} \mathrm{ApoE}^{-/-}$had the largest plaques $(230112 \pm 20124)$ versus female $\mathrm{ApoE}^{-/-}(188057 \pm 15816) p=0.0587$ (Figure 5(a)). In the ascending aorta, there was a trend for
$\mathrm{GK}^{+/-} \mathrm{ApoE}^{-/-}$mice to have larger lesions with less variability compared with $\mathrm{ApoE}^{-/-}$(Figure 5(b)). However, statistically significant difference was seen only with female mice on Lard diet $\left(\mathrm{GK}^{+/-} \mathrm{ApoE}^{-/-}\right.$versus ApoE ${ }^{-/-}, 2602000 \pm 403800$ versus $1355000 \pm 297600, p=0.0115$ ) (males on Lard: $\mathrm{GK}^{+/-} \mathrm{ApoE}^{-/-}$versus ApoE ${ }^{-/-} 4284000 \pm 615660$ versus $3201000 \pm 465241, p=0.0858)$.

On lard diet, there was also a trend in BCA for female $\mathrm{GK}^{+/-} \mathrm{ApoE}^{-/-}$to have the largest plaque $(228298 \pm 22675)$ versus female $\mathrm{ApoE}^{-/-}(190804 \pm 16158), p=0.0974$. There were no statistically significant differences in plaque size in the brachiocephalic artery (WD $220188 \pm 12279$ versus $199578 \pm 9759$, Lard $264854 \pm 28916$ versus $286013 \pm 23494)$ on either high-fat diets for the male group $\left(\mathrm{GK}^{+/-} \mathrm{ApoE}{ }^{-/-}\right.$ versus $\left.\mathrm{ApoE}^{-/-}\right)$. Lesion was equally advanced in the brachiocephalic artery in the two strains illustrated in Figure 6.

3.3.2. Atheroregression. Despite lower plasma cholesterol levels in both males and females $\mathrm{GK}^{+/-} \mathrm{ApoE}^{-/-}$and $\mathrm{ApoE}^{-/-}$ mice after dietary change (Lard to Chow diet) compared with the Lard to WD (Figure 7(a)), plaque size in the brachiocephalic artery (Figure 7(b)) and in the aortic sinus (Figure 7(c)) remained comparable. In other vascular sites, there was also impaired lesion regression (en face lesion area in thoracic aorta, ascending aorta, and left coronary artery) (data not presented).

3.4. Coronary Flow Velocity Reserve (CFVR). Basal flow velocity and hyperemic flow velocity $(\mathrm{cm} / \mathrm{s})$ were not significantly different in either genotype. Furthermore, CFVR was not significantly different between $\mathrm{ApoE}^{-/-}$and $\mathrm{GK}^{+/-} \mathrm{ApoE}^{-/-}$ at 18 weeks of age (Table 2 ).

\section{Discussion}

The present study characterized heterozygous glucokinase knockout apolipoprotein $\mathrm{E}$ deficient mice $\left(\mathrm{GK}^{+/-} \mathrm{ApoE}^{-/-}\right)$, a novel mouse model of diabetes and atherosclerosis. We demonstrate that this mouse model has very stable hyperglycemia, indications of increased atherosclerosis development on high-fat diet, and impaired lesion regression after lipid lowering. The atherosclerosis is stable on WD and the $\mathrm{GK}^{+/-} \mathrm{ApoE}^{-/-}$knockout shows comparable coronary vascular function to the apolipoprotein $\mathrm{E}$ (ApoE) deficient mice at 18 weeks of age.

For a rodent model to be considered T2D model, fasting blood glucose levels of around $150-300 \mathrm{mg} / \mathrm{dL}^{-1}(8.3-$ $16.7 \mathrm{mmol} / \mathrm{L}$ ) are recommended [16]. Our model has glucose levels which exceed the minimum threshold and should therefore be considered as a diabetic model. There are other commonly used animal models of T2D (leptin-mutated $\mathrm{ob} / \mathrm{ob}$, leptin-receptor deficient $\mathrm{db} / \mathrm{db}$ mice, and male missense mutated leptin-receptor Zucker Diabetic Fatty (ZDF) rats); however, they have a wide but unstable hyperglycemic range $[12,17]$. In the fasted state, insulin levels were similar between the $\mathrm{GK}^{+/-} \mathrm{ApoE}^{-/-}$knockout mice and the ApoE $\mathrm{E}^{-/-}$ mice despite higher glucose levels in the $\mathrm{GK}^{+/-} \mathrm{ApoE}^{-/-}$. 


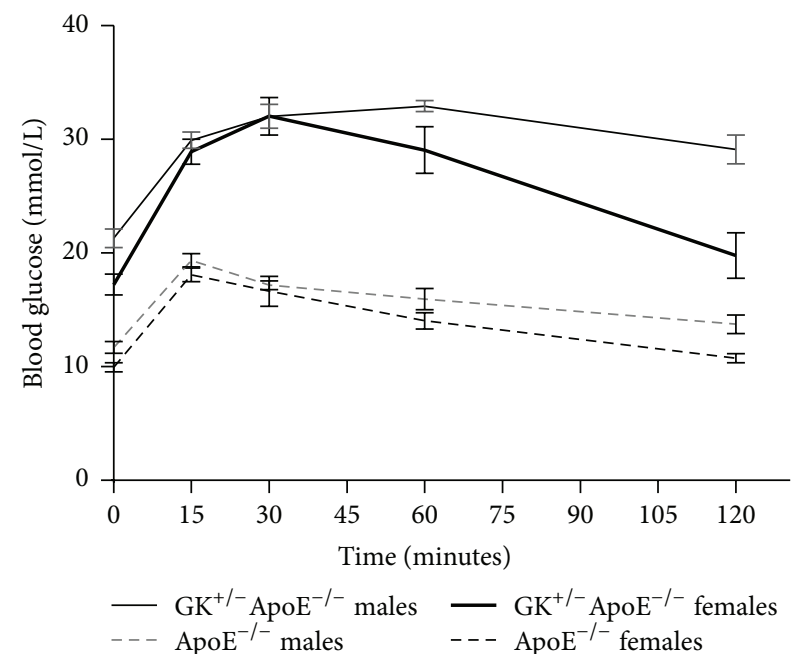

(a)

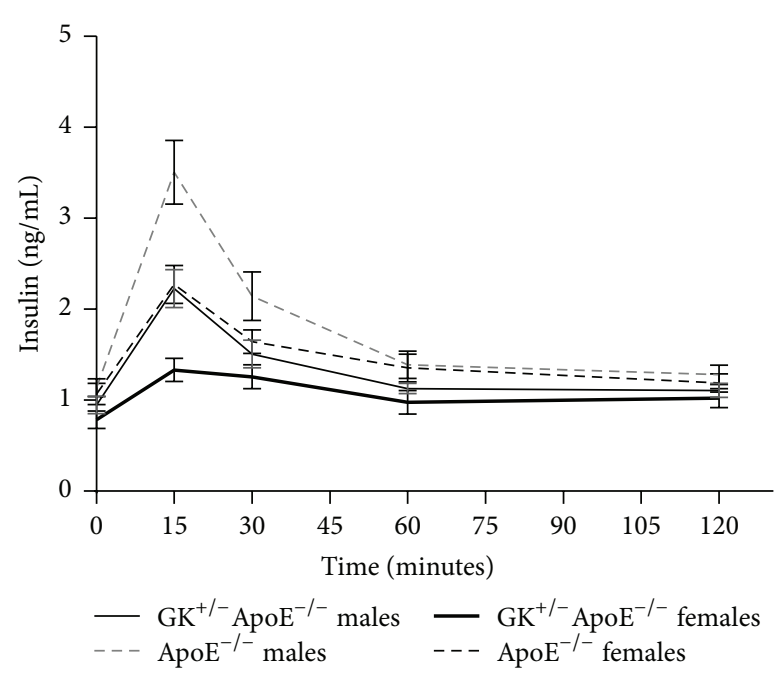

(c)

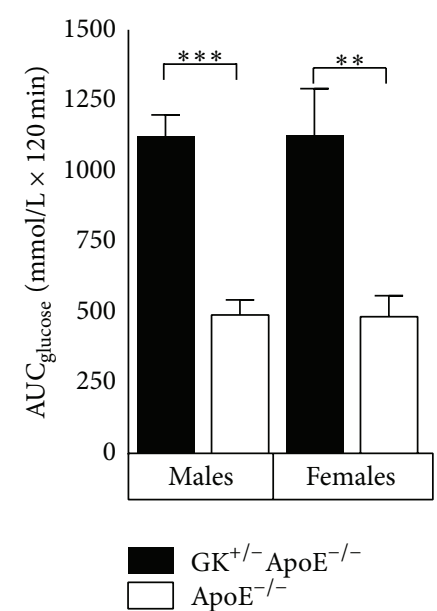

(b)

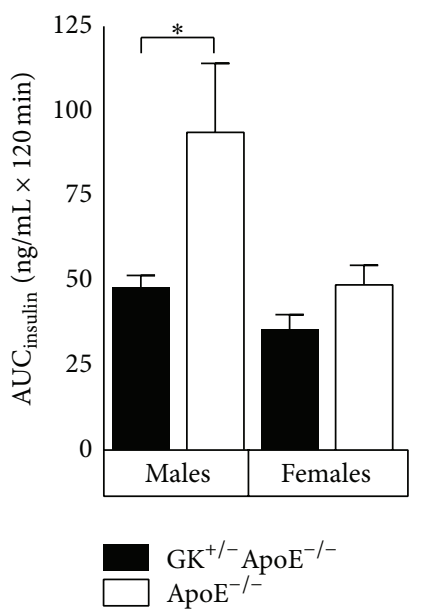

(d)

Figure 4: Oral Glucose tolerance test ((a) and (b)) and insulin ((c) and (d)) in the $\mathrm{GK}^{+/-} \mathrm{ApoE}^{-/-}$mice compared with the ApoE ${ }^{-/-}$mice after 14 weeks on Western diet. Both male and female $\mathrm{GK}^{+/-} \mathrm{ApoE}^{-/-}$mice display significantly impaired glucose-stimulated insulin secretion. Values are presented as means and standard error of mean (SEM). ${ }^{*} p<0.05,{ }^{* *} p<0.005$, and ${ }^{* * *} p<0.0001$.

Higher glucose levels in the $\mathrm{GK}^{+/-} \mathrm{ApoE}^{-/-}$would be expected to result in even higher insulin levels. This however was not the case, indicating that the hyperglycemia in the $\mathrm{GK}^{+/-} \mathrm{ApoE}^{-/-}$knockout mice is predominantly due to inadequate compensatory insulin secretory response, possibly as a result of impaired $\beta$-cell function, an important determinant of type 2 diabetes $[18,19]$. Insulin level measurement is an acceptable measure to indicate $\beta$-cell function in rodent models [20]; our findings are consistent with insulin response pattern in humans with advanced type 2 diabetes, where there is an insufficient insulin secretion to meet demand [19].

The $\mathrm{GK}^{+/-}$mouse model has been suggested to be a representative model of type 2 diabetes, which encompasses both the hepatic and the $\beta$-cell GK deficiencies found to occur in the disease [11]. On a high-fat diet, the $\mathrm{GK}^{+/-}$mouse has reduced islet GK activity and defects in glucose-stimulated insulin secretion [11, 21]; our current diabetic phenotype data on $\mathrm{GK}^{+/-} \mathrm{ApoE}^{-/-}$knockout mice are comparable to those previously published on the $\mathrm{GK}^{+-}$by above-mentioned authors. This indicates that the hepatic and the $\beta$-cell GK deficiencies in the parent $\mathrm{GK}^{+/-}$mice when cross-breed with the $\mathrm{ApoE}^{-/-}$were transferred to the offspring $\mathrm{GK}^{+/-} \mathrm{ApoE}^{-/-}$ knockout mice.

The $\mathrm{ApoE}^{-/-}$is a widely used mouse model of atherosclerosis [22]. Plasma lipid levels were comparable between the $\mathrm{GK}^{+/-} \mathrm{ApoE}^{-/-}$and the $\mathrm{ApoE}^{-/-}$mice, but nevertheless the $\mathrm{GK}^{+/-} \mathrm{ApoE}^{-/-}$mice showed slightly higher plaque burden in line with atherosclerotic progression in human T2D [23], as well as impaired lesion regression at different vascular sites. Even though the plaque burden is slightly higher in the $\mathrm{GK}^{+/-} \mathrm{ApoE}^{-/-}$compared to the $\mathrm{ApoE}^{-/-}$, both genotypes 
TABLE 1: Lipid levels in $\mathrm{GK}^{+/-} \mathrm{ApoE}^{-/-}$and $\mathrm{ApoE}^{-/-}$mice on Lard and Western diet measured in the atheroprogression study.

\begin{tabular}{|c|c|c|c|c|c|c|}
\hline Diet & Gender & Time & Genotype & Cholesterol (mmol/L) & $\mathrm{TG}(\mathrm{mmol} / \mathrm{L})$ & NEFA \\
\hline \multirow{12}{*}{ Lard } & \multirow{6}{*}{ Males } & \multirow{2}{*}{3 weeks } & $\mathrm{ApoE}^{-/-}$ & $38.86 \pm 1.11$ & - & - \\
\hline & & & $\mathrm{GK}^{+/-} \mathrm{ApoE}^{-/-}$ & $35.84 \pm 1.91$ & - & - \\
\hline & & \multirow{2}{*}{7 weeks } & $\mathrm{ApoE}^{-/-}$ & $38.20 \pm 1.46$ & - & - \\
\hline & & & $\mathrm{GK}^{+/-} \mathrm{ApoE}^{-/-}$ & $31.00 \pm 1.52$ & - & - \\
\hline & & \multirow{2}{*}{14 weeks } & $\mathrm{ApoE}^{-/-}$ & $38.32 \pm 1.48$ & $1.21 \pm 0.11$ & $0.49 \pm 0.02$ \\
\hline & & & $\mathrm{GK}^{+/-} \mathrm{ApoE}^{-/-}$ & $30.84 \pm 1.81$ & $0.86 \pm 0.14$ & $0.45 \pm 0.02$ \\
\hline & \multirow{6}{*}{ Females } & \multirow{2}{*}{3 weeks } & $\mathrm{ApoE}^{-/-}$ & $25.88 \pm 1.00$ & - & - \\
\hline & & & $\mathrm{GK}^{+/-} \mathrm{ApoE}^{-/-}$ & $22.78 \pm 1.73$ & - & - \\
\hline & & \multirow{2}{*}{7 weeks } & $\mathrm{ApoE}^{-/-}$ & $25.20 \pm 0.97$ & - & - \\
\hline & & & $\mathrm{GK}^{+/-} \mathrm{ApoE}^{-/-}$ & $23.40 \pm 1.12$ & - & - \\
\hline & & \multirow{2}{*}{14 weeks } & $\mathrm{ApoE}^{-/-}$ & $20.58 \pm 0.62$ & $0.52 \pm 0.13$ & $0.55 \pm 0.04$ \\
\hline & & & $\mathrm{GK}^{+/-} \mathrm{ApoE}^{-/-}$ & $20.11 \pm 0.82$ & $0.27 \pm 0.06$ & $0.50 \pm 0.03$ \\
\hline \multirow{12}{*}{ Western } & \multirow{6}{*}{ Males } & \multirow{2}{*}{3 weeks } & $\mathrm{ApoE}^{-/-}$ & $20.84 \pm 1.21$ & - & - \\
\hline & & & $\mathrm{GK}^{+/-} \mathrm{ApoE}^{-/-}$ & $17.42 \pm 2.47$ & - & - \\
\hline & & \multirow{2}{*}{7 weeks } & $\mathrm{ApoE}^{-/-}$ & $22.40 \pm 0.75$ & - & - \\
\hline & & & $\mathrm{GK}^{+/-} \mathrm{ApoE}^{-/-}$ & $18.80 \pm 2.82$ & - & - \\
\hline & & \multirow{2}{*}{21 weeks } & $\mathrm{ApoE}^{-/-}$ & $31.65 \pm 2.16$ & $0.82 \pm 0.09$ & $0.39 \pm 0.02$ \\
\hline & & & $\mathrm{GK}^{+/-} \mathrm{ApoE}^{-/-}$ & $27.88 \pm 2.78$ & $0.81 \pm 0.13$ & $0.44 \pm 0.02$ \\
\hline & \multirow{6}{*}{ Females } & \multirow{2}{*}{3 weeks } & $\mathrm{ApoE}^{-/-}$ & $17.54 \pm 1.04$ & - & - \\
\hline & & & $\mathrm{GK}^{+/-} \mathrm{ApoE}^{-/-}$ & $20.62 \pm 1.19$ & - & - \\
\hline & & \multirow{2}{*}{7 weeks } & $\mathrm{ApoE}^{-/-}$ & $18.60 \pm 0.51$ & - & - \\
\hline & & & $\mathrm{GK}^{+/-} \mathrm{ApoE}^{-/-}$ & $18.40 \pm 1.08$ & - & - \\
\hline & & \multirow{2}{*}{21 weeks } & $\mathrm{ApoE}^{-/-}$ & $23.35 \pm 1.57$ & $0.36 \pm 0.05$ & $0.45 \pm 0.03$ \\
\hline & & & $\mathrm{GK}^{+/-} \mathrm{ApoE}^{-1-}$ & $20.57 \pm 2.45$ & $0.38 \pm 0.06$ & $0.43 \pm 0.03$ \\
\hline
\end{tabular}

Lard diet induced higher cholesterol levels than Western diet. There is a trend for $\mathrm{ApoE}^{-/-}$mice to have higher cholesterol, triglycerides, and nonesterified fatty acids (NEFA) levels compared with $\mathrm{GK}^{+/-} \mathrm{ApoE}^{-/-}$. Data presented as mean \pm SEM.

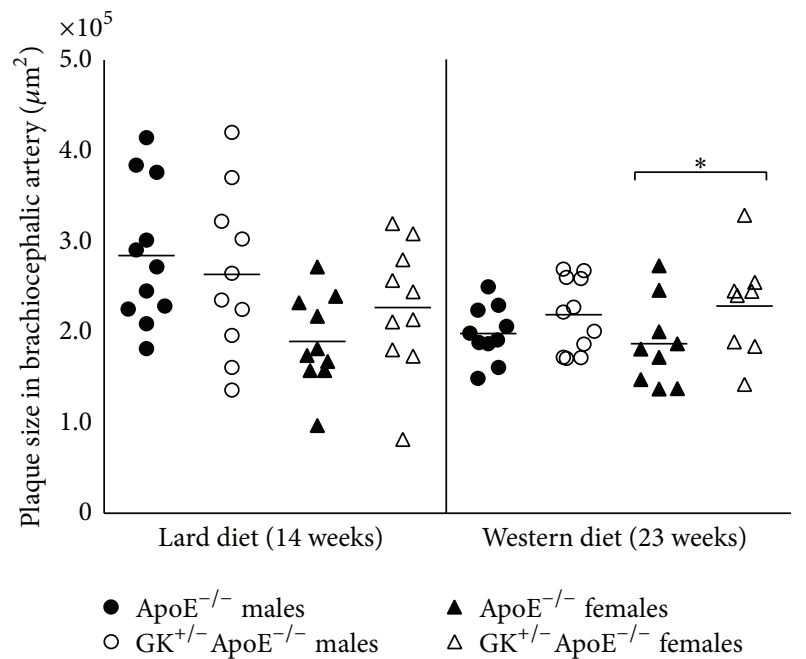

(a)

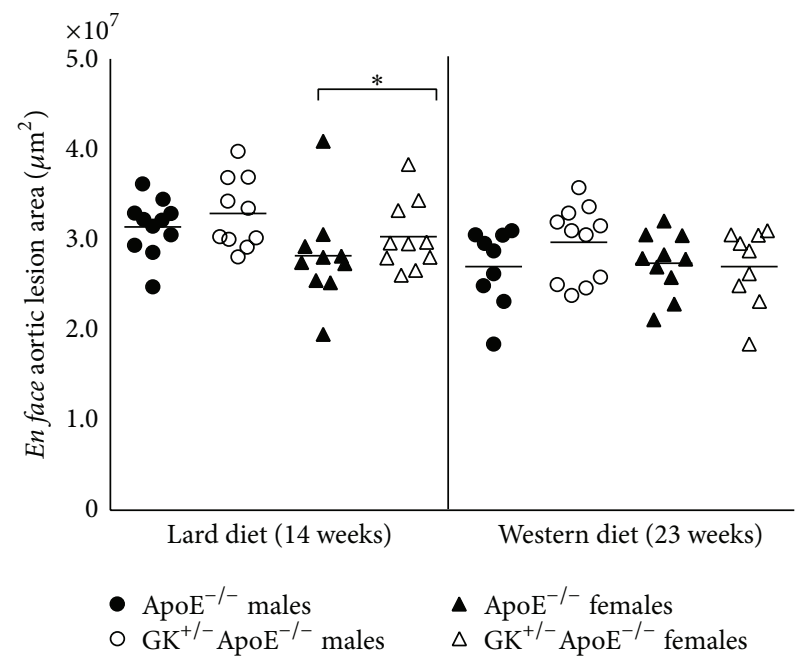

(b)

FIGURE 5: Histology evaluation of plaque size in the brachiocephalic artery (a) and en face lesion area in the thoracic aorta (b) measured in the atheroprogression study. There is a trend for $\mathrm{GK}^{+/} \mathrm{ApoE}^{-/-}$mice to have greater plaque compared with the ApoE ${ }^{-/-}$, with female $\mathrm{GK}^{+/-} \mathrm{ApoE}^{-/-}$having a more consistent pattern. Statistical analysis was performed using $t$-test and a $p$ value of less than 0.05 was considered significant. ${ }^{*} p<0.05$. 


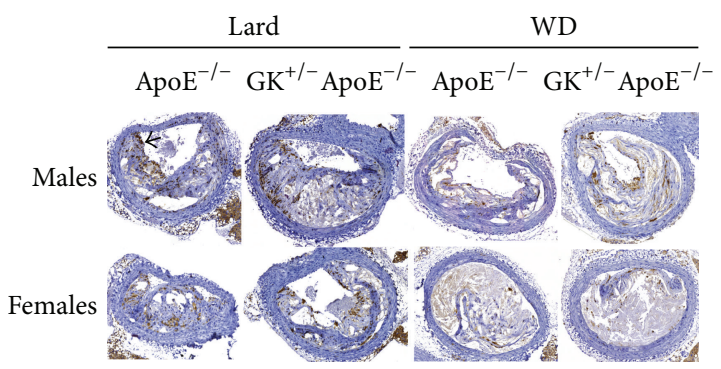

(a)

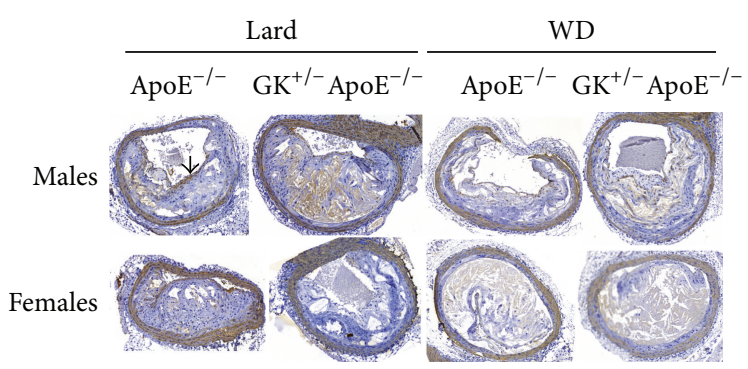

(b)

FIGURE 6: The atherosclerotic lesions of the brachiocephalic artery in both genotypes have become advanced and complicated after Lard and WD for 14 and 23 weeks, respectively. Large areas of the lesions consist of necrotic core and cholesterol clefts. (a) Only a few scattered macrophages (brown indicated by arrow on the figure) are detected by the macrophage antibody. (b) Smooth muscle cells (brown) are detected in the vessel wall by the alpha-actin antibody. A thin cap is sometimes seen in the lesions, indicated by arrow on the figure. Images in Figures 6(a) and 6(b) are consecutive sections from the same animal.

TABlE 2: Coronary flow velocity in female $\mathrm{ApoE}^{-/-}$and $\mathrm{GK}^{+/-} \mathrm{ApoE}^{-/-}$mice at 18 weeks old.

\begin{tabular}{lcc}
\hline & $\begin{array}{c}\text { ApoE } \\
(n=17)\end{array}$ & $\begin{array}{c}\mathrm{GK}^{+/-} \mathrm{ApoE}^{-/-} \\
(n=14)\end{array}$ \\
\hline Basal flow velocity $(\mathrm{cm} / \mathrm{s})$ & $35.1 \pm 2.5$ & $34.4 \pm 2.7$ \\
Hyperemic flow velocity $(\mathrm{cm} / \mathrm{s})$ & $59.1 \pm 2.1$ & $60.6 \pm 2.3$ \\
CFVR & $1.76 \pm 0.18$ & $1.86 \pm 0.10$ \\
\hline
\end{tabular}

Data presented as mean \pm SEM.

develop advanced and complicated lesions. There are only few detectable macrophages and thin protecting caps, if any. On the other hand, both genotypes have necrotic cores, cholesterol clefts, buried caps, and layered phenotype, hallmarks of complicated mice lesions [24]. Several clinical studies have shown in populations with atherosclerosis that dietary intervention may reduce the progression of the atherosclerotic plaque development $[25,26]$ and regression mediated by weight loss may even occur [27]. Furthermore, there are also data suggesting that coronary atherosclerosis may be regressed by diet and comprehensive lifestyle changes $[28,29]$. For studies using animal models to investigate treatments targeting cardiovascular disease in diabetes, it is important that diabetic and atherosclerotic disease is stable.

This mouse model showed comparable coronary vascular function to the apolipoprotein $\mathrm{E}$ (ApoE) deficient mice at 18 weeks of age. Although there were no significant differences between the $\mathrm{GK}^{+/-} \mathrm{ApoE}^{-/-}$and the $\mathrm{ApoE}^{-/-}$mice for coronary vascular function, values presented here for basal flow velocity and CFVR measured in both genotypes are higher and lower, respectively, when compared to published data for $\mathrm{C} 57 \mathrm{Bl} / 6 \mathrm{~J}-\mathrm{lep}{ }^{\mathrm{ob}}$ and age matched lean litter mates $(+/$ ? $)$ of comparable age [30]. Furthermore, in a study by Hartley et al. [15], they showed that old $\mathrm{ApoE}^{-/-}$(2 years of age) mice have a higher baseline flow velocity and lower CFVR when compared to the $\mathrm{ApoE}^{+/+}$wild-type mice of similar age, which is in agreement with our findings [15]. Baseline coronary flow is based on cardiac metabolic demand (hemoglobin content, oxygen saturation, and baseline hemodynamics) [31, 32], and it is reasonable to assume that the high blood glucose and cholesterol in the $\mathrm{GK}^{+/-} \mathrm{ApoE}^{-/-}$and the $\mathrm{ApoE}^{-/-}$mice will negatively influence their hemoglobin content, thereby increasing metabolic demand reflected by higher basal flow velocity. Correlation between CFVR and coronary atherosclerosis has been shown in mice [33]; furthermore, CFVR is reduced in atherosclerotic mice $[32,33]$. In agreement, we observed low CFVR values in our mice model at 18 weeks of age and comparable plaque burden in the $\mathrm{GK}^{+/-} \mathrm{ApoE}^{-/-}$and the $\mathrm{ApoE}^{-/-}$mice, supporting the lack of difference in the CFVR between the strains and emphasizing macrovascular burden to underlie the coronary vascular dysfunction. In man, CFVR is used to evaluate the severity of different cardiac pathologies and values ranging from 2.5 to 5.0 have been reported, with $>3.0$ used as the lower limit of normal [31]. Validation studies on the $\mathrm{GK}^{+/-} \mathrm{ApoE}^{-/-}$are currently ongoing within our lab to characterize changes in coronary vascular function over time (mice from 6 weeks of age) using ultrasonography and to investigate effect of lipid lowering and standard-of-care treatments for diabetes.

The strength of the $\mathrm{GK}^{+/-} \mathrm{ApoE}^{-/-}$mice lies in that it has stable hyperglycemia, and diabetes is not progressive. This makes it possible to use either young or old mice to carry out short or long studies without the disease phenotype changing with age. The ZDF rats and ob/ob or db/db mice have limited age window for treatments due to rapid disease progression and large variability, which requires large group sizes. These other rodent models of T2D (ZDF rats and ob/ob or $\mathrm{db} / \mathrm{db}$ mice) are monogenic models of obesity which induces hyperglycemia, which weakens their translational value as obesity is seldom caused by a monogenic mutation $[17,20]$. Diabetes induced by Streptozotocin (STZ) provides a nonphysiological model, with variation dependent on STZ dose and sometimes severe adverse effect on rodents [34]. In the relatively long period of monitoring the $\mathrm{GK}^{+/-} \mathrm{ApoE}^{-/-}$(up to 21 weeks), fasting blood glucose and cholesterol remained high and stable. This makes the $\mathrm{GK}^{+/-} \mathrm{ApoE}^{-/-}$model suitable for investigations related to the combination of diabetes and atherosclerosis. 


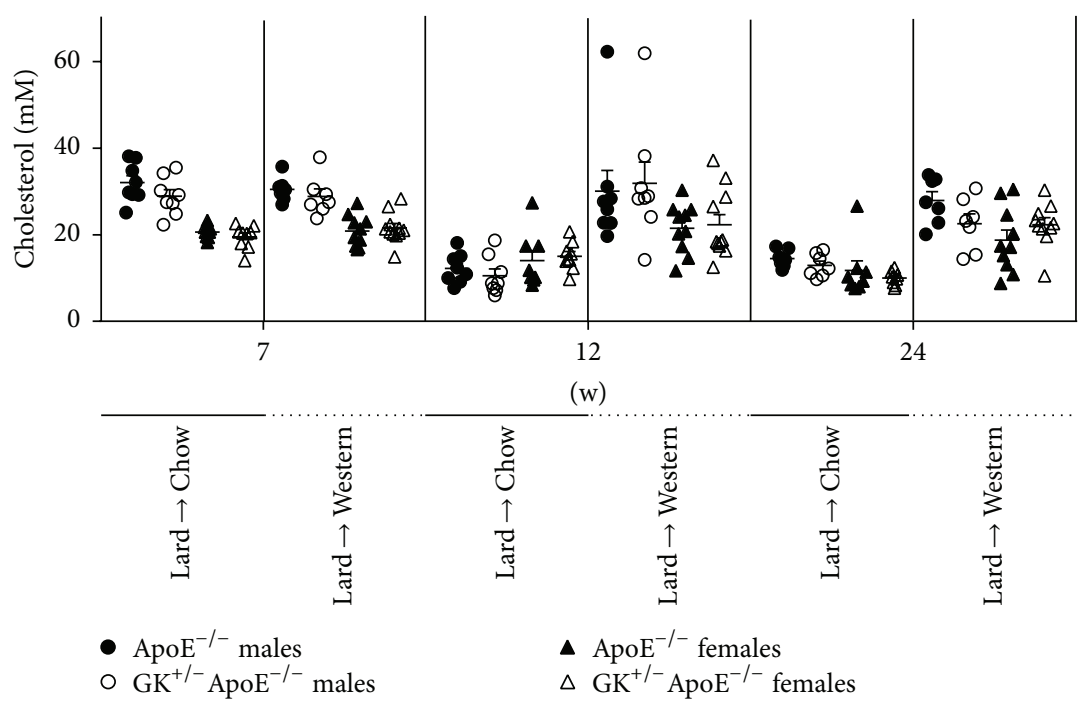

(a)

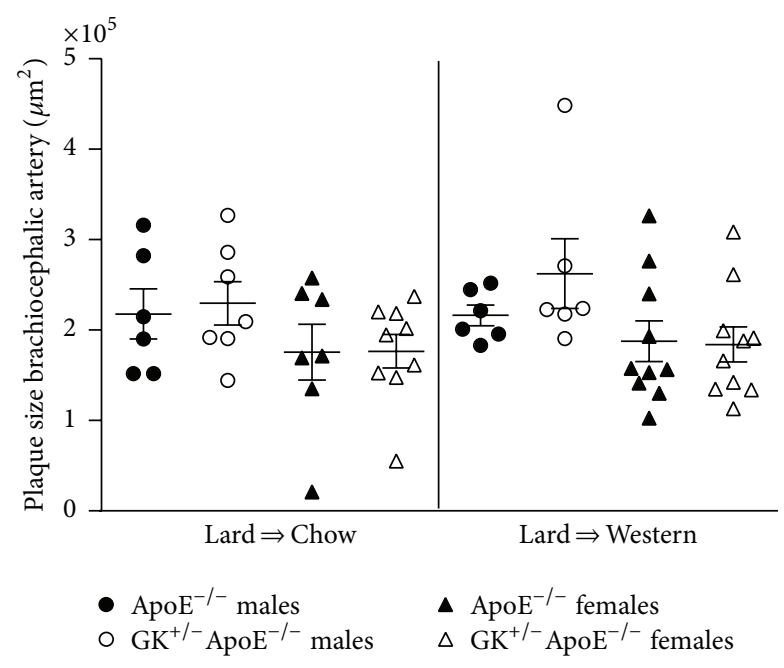

(b)

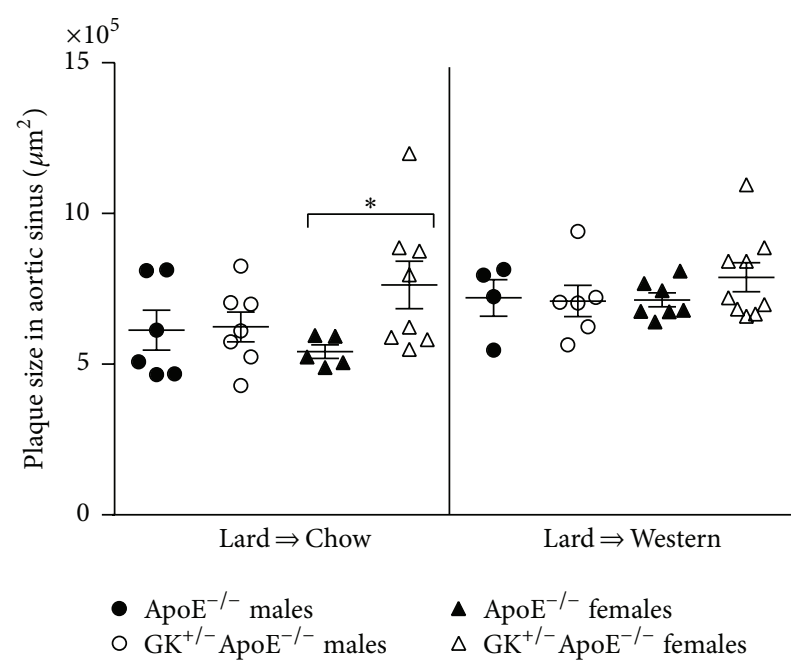

(c)

FIGURE 7: Nonfasting total plasma cholesterol measured after 7 weeks on Lard diet, 4 weeks after diet changed from Lard to WD or Lard to Chow, and 14 weeks after diet changed from Lard to WD or Lard to Chow (a). Plaque size in the brachiocephalic artery (b) and aortic sinus plaque size (c) measured after 14 weeks on Lard to WD or Lard to Chow diet in the atheroregression study. (a) Priming mice with Lard diet induced a 3-fold increase in total cholesterol and the levels remained the same after changing to WD, resulting in similar cholesterol levels at 7 weeks. Conversely, after switching from Lard to Chow diet, the total cholesterol levels decreased significantly in all groups. (b) Plaque sizes in the brachiocephalic artery in both diet groups were comparable, which indicates that the atherosclerosis did not regress on the Lard to Chow diet change. (c). Female $\mathrm{GK}^{+/-} \mathrm{ApoE}^{-/-}$mice show equal amount of plaque in the aortic sinus in the Lard to Chow group compared to the Lard to WD despite lower plasma cholesterol levels in both $\mathrm{GK}^{+-} \mathrm{ApoE}^{-/-}$and $\mathrm{ApoE}^{-/-}$mice after dietary change (Lard to Chow diet). Statistical analysis was performed using $t$-test and a $p$ value of less than 0.05 was considered significant. ${ }^{*} p<0.05$.

For decades, new diabetes drugs were approved primarily based on their glucose-lowering efficacy. However, after observations of increased cardiovascular risk with some medications, the regulatory agencies now demand studies showing that novel antidiabetic agents are at least neutral in their cardiovascular effects [35]. Although these new regulatory requirements as such apply only for clinical trials, they affect also preclinical research, as more accurate prediction of the cardiovascular effects is warranted. Secondly, instead of aiming just for cardiovascular neutrality, the future medical treatments will favor compounds that have beneficial cardiovascular effects in addition to their antidiabetic action (multifunctional compounds with hypolipidemic and antidiabetic action). Therefore, we need pharmacokinetic: pharmacodynamics (PK/PD) models, where both metabolic and cardiovascular endpoints can be studied in one and the same animal.

There are several positives in this novel animal model. The animal model has a stable hyperglycemic phenotype that is very reproducible from batch to batch, and there is little 
variation so that relatively small group sizes can be used. Diabetes does not cause increases in lipid levels, which is unlike most of the other used diabetes models. The etiology is rather relevant, since individuals with T2D exhibit high rates of hepatic glucose output and have reduced GK activity in liver and pancreas. These mice do not have any special health problems, so they are easy to breed and use in short- or long-term studies. The lipid profile is a negative against this model, since the $\mathrm{ApoE}^{-/-}$mice are a remnant model and thus do not resemble much the human lipoprotein profile and lack also all the other functions of ApoE. Reviewing the lipid levels shows that there is no exceptional difference in the $\mathrm{GK}^{+/-} \mathrm{ApoE}^{-/-}$compared with the $\mathrm{ApoE}^{-/-}$. Moreover, the diabetic $\mathrm{GK}^{+/-} \mathrm{ApoE}^{-/-}$mice have a bit lower cholesterol and TG levels, which can be due to reduced GK activity in the liver and thus reduced lipogenesis. This is an important feature, since normally when diabetes is induced in mice, for example, with STZ or by crossing $\mathrm{db} / \mathrm{db}$ mice with dyslipidemic strains, the lipid levels increase significantly and as a result supraphysiological lipid levels that easily overrun all other factors.

\section{Conclusions}

We conclude that, compared to normoglycemic $\mathrm{ApoE}^{-/-}$ mice, the $\mathrm{GK}^{+/-} \mathrm{ApoE}^{-/-}$mice showed a stable and reproducible hyperglycemia, which induced accelerated atherosclerotic lesion progression as well as impaired lesion regression after lipid lowering. Importantly, these effects were seen without increases in plasma lipid levels. This novel model provides a promising tool for drug discovery, enabling the evaluation of compound effects against both diabetic and cardiovascular endpoints simultaneously in one animal model.

\section{Disclosure}

Damilola D. Adingupu and Suvi E. Heinonen are joint first authors.

\section{Competing Interests}

The authors declare that they have no competing interests.

\section{Authors' Contributions}

Damilola D. Adingupu and Suvi E. Heinonen contributed equally to this work.

\section{Acknowledgments}

The authors thank Anna Tuneld and Gun-Britt Forsberg for excellent analytical support. We are also indebted to the animal facility at AstraZeneca in Alderly Park, UK, for the breeding of the mice and to the animal facility at AstraZeneca Mölndal, Sweden, for husbandry and help with blood sampling.

\section{References}

[1] G. Danaei, M. M. Finucane, Y. Lu et al., "National, regional, and global trends in fasting plasma glucose and diabetes prevalence since 1980: systematic analysis of health examination surveys and epidemiological studies with 370 country-years and 2.7 million participants," The Lancet, vol. 378, no. 9785, pp. 31-40, 2011.

[2] M. A. Creager, T. F. Lüscher, F. Cosentino, and J. A. Beckman, "Diabetes and vascular disease: pathophysiology, clinical consequences, and medical therapy-part I," Circulation, vol. 108, no. 12, pp. 1527-1532, 2003.

[3] T. F. Lüscher, M. A. Creager, J. A. Beckman, and F. Cosentino, "Diabetes and vascular disease: pathophysiology, clinical consequences, and medical therapy-part II," Circulation, vol. 108, no. 13, pp. 1655-1661, 2003.

[4] M. Coghlan and B. Leighton, "Glucokinase activators in diabetes management," Expert Opinion on Investigational Drugs, vol. 17, no. 2, pp. 145-167, 2008.

[5] F. M. Matschinsky, "Assessing the potential of glucokinase activators in diabetes therapy," Nature Reviews Drug Discovery, vol. 8, no. 5, pp. 399-416, 2009.

[6] K. K. Osbak, K. Colclough, C. Saint-Martin et al., "Update on mutations in glucokinase (GCK), which cause maturity-onset diabetes of the young, permanent neonatal diabetes, and hyperinsulinemic hypoglycemia," Human Mutation, vol. 30, no. 11, pp. 1512-1526, 2009.

[7] J. F. Caro, S. Triester, V. K. Patel, E. B. Tapscott, N. L. Frazier, and G. L. Dohm, "Liver glucokinase: decreased activity in patients with type II diabetes," Hormone and Metabolic Research, vol. 27, no. 1, pp. 19-22, 1995.

[8] A. Basu, R. Basu, P. Shah et al., "Effects of type 2 diabetes on the ability of insulin and glucose to regulate splanchnic and muscle glucose metabolism: evidence for a defect in hepatic glucokinase activity," Diabetes, vol. 49, no. 2, pp. 272-283, 2000.

[9] A. Basu, R. Basu, P. Shah et al., "Type 2 diabetes impairs splanchnic uptake of glucose but does not alter intestinal glucose absorption during enteral glucose feeding: additional evidence for a defect in hepatic glucokinase activity," Diabetes, vol. 50, no. 6, pp. 1351-1362, 2001.

[10] S. Del Guerra, R. Lupi, L. Marselli et al., "Functional and molecular defects of pancreatic islets in human type 2 diabetes," Diabetes, vol. 54, no. 3, pp. 727-735, 2005.

[11] T. Gorman, D. C. D. Hope, R. Brownlie et al., "Effect of high-fat diet on glucose homeostasis and gene expression in glucokinase knockout mice," Diabetes, Obesity and Metabolism, vol. 10, no. 10, pp. 885-897, 2008.

[12] D. J. Baker, A. M. Atkinson, G. P. Wilkinson, G. J. Coope, A. D. Charles, and B. Leighton, "Characterization of the heterozygous glucokinase knockout mouse as a translational disease model for glucose control in type 2 diabetes," British Journal of Pharmacology, vol. 171, no. 7, pp. 1629-1641, 2014.

[13] D. J. Baker, G. P. Wilkinson, A. M. Atkinson et al., "Chronic glucokinase activator treatment at clinically translatable exposures gives durable glucose lowering in two animal models of type 2 diabetes," British Journal of Pharmacology, vol. 171, no. 7, pp. 1642-1654, 2014.

[14] C. Kilkenny, W. Browne, I. C. Cuthill, M. Emerson, and D. G. Altman, "Animal research: reporting in vivo experiments: the ARRIVE guidelines," British Journal of Pharmacology, vol. 160, no. 7, pp. 1577-1579, 2010. 
[15] C. J. Hartley, A. K. Reddy, S. Madala, L. H. Michael, M. L. Entman, and G. E. Taffet, "Effects of isoflurane on coronary blood flow velocity in young, old and $\mathrm{ApoE}^{-/-}$mice measured by doppler ultrasound," Ultrasound in Medicine and Biology, vol. 33, no. 4, pp. 512-521, 2007.

[16] E. H. Leiter, "Selecting the 'right' mouse model for metabolic syndrome and type 2 diabetes research," in Type 2 Diabetes: Methods and Protocols, C. Stocker, Ed., Humana Press, Totowa, NJ, USA, 2009.

[17] P. Lindstrom, "The physiology of obese-hyperglycemic mice [ob/ob mice]," TheScientificWorldJournal, vol. 7, pp. 666-685, 2007.

[18] American Diabetes Association, "Diagnosis and classification of diabetes mellitus," Diabetes Care, vol. 32, supplement 1, pp. S62-S67, 2009.

[19] M. E. Cerf, "Beta cell dysfunction and insulin resistance," Frontiers in Endocrinology, vol. 4, article 37, 2013.

[20] A. J. F. King, "The use of animal models in diabetes research," British Journal of Pharmacology, vol. 166, no. 3, pp. 877-894, 2012.

[21] Y. Terauchi, I. Takamoto, N. Kubota et al., "Glucokinase and IRS- 2 are required for compensatory $\beta$ cell hyperplasia in response to high-fat diet-induced insulin resistance," The Journal of Clinical Investigation, vol. 117, no. 1, pp. 246-257, 2007.

[22] A. A. Pendse, J. M. Arbones-Mainar, L. A. Johnson, M. K. Altenburg, and N. Maeda, "Apolipoprotein E knock-out and knock-in mice: atherosclerosis, metabolic syndrome, and beyond," Journal of Lipid Research, vol. 50, pp. S178-S182, 2009.

[23] C.-H. Yun, C. L. Schlett, I. S. Rogers et al., "Association between diabetes and different components of coronary atherosclerotic plaque burden as measured by coronary multidetector computed tomography," Atherosclerosis, vol. 205, no. 2, pp. 481-485, 2009.

[24] H. Williams, J. L. Johnson, K. G. S. Carson, and C. L. Jackson, "Characteristics of intact and ruptured atherosclerotic plaques in brachiocephalic arteries of apolipoprotein E knockout mice," Arteriosclerosis, Thrombosis, and Vascular Biology, vol. 22, no. 5, pp. 788-792, 2002.

[25] R. P. Wildman, L. L. Schott, S. Brockwell, L. H. Kuller, and K. Sutton-Tyrrell, "A dietary and exercise intervention slows menopause-associated progression of subclinical atherosclerosis as measured by intima-media thickness of the carotid arteries," Journal of the American College of Cardiology, vol. 44, no. 3, pp. 579-585, 2004.

[26] E. M. Hjerkinn, M. Abdelnoor, L. Breivik et al., "Effect of diet or very long chain $\omega$-3 fatty acids on progression of atherosclerosis, evaluated by carotid plaques, intima-media thickness and by pulse wave propagation in elderly men with hypercholesterolaemia," European Journal of Cardiovascular Prevention and Rehabilitation, vol. 13, no. 3, pp. 325-333, 2006.

[27] I. Shai, J. D. Spence, D. Schwarzfuchs et al., "Dietary intervention to reverse carotid atherosclerosis," Circulation, vol. 121, no. 10, pp. 1200-1208, 2010.

[28] D. Ornish, S. E. Brown, J. H. Billings et al., "Can lifestyle changes reverse coronary heart disease?” The Lancet, vol. 336, no. 8708, pp. 129-133, 1990.

[29] G. F. Watts, B. Lewis, E. S. Lewis et al., "Effects on coronary artery disease of lipid-lowering diet, or diet plus cholestyramine, in the St Thomas' Atherosclerosis Regression Study (STARS)," The Lancet, vol. 339, no. 8793, pp. 563-569, 1992.

[30] H. U. Westergren, J. Grönros, S. E. Heinonen et al., "Impaired coronary and renal vascular function in spontaneously type 2 diabetic leptin-deficient mice," PLoS ONE, vol. 10, no. 6, Article ID e0130648, 2015.

[31] P. P. Dimitrow, M. Galderisi, and F. Rigo, "The non-invasive documentation of coronary microcirculation impairment: role of transthoracic echocardiography," Cardiovascular Ultrasound, vol. 3, article 18, 2005.

[32] J. Wikström, J. Grönros, and L.-M. Gan, "Adenosine induces dilation of epicardial coronary arteries in mice-relationship between coronary flow velocity reserve and coronary flow reserve in vivo using transthoracic echocardiography," Ultrasound in Medicine and Biology, vol. 34, no. 7, pp. 1053-1062, 2008.

[33] J. Wikström, J. Grönros, G. Bergström, and L.-M. Gan, "Functional and morphologic imaging of coronary atherosclerosis in living mice using high-resolution color Doppler echocardiography and ultrasound biomicroscopy," Journal of the American College of Cardiology, vol. 46, no. 4, pp. 720-727, 2005.

[34] M. L. Graham, J. L. Janecek, J. A. Kittredge, B. J. Hering, and H.-J. Schuurman, "The streptozotocin-induced diabetic nude mouse model: differences between animals from different sources," Comparative Medicine, vol. 61, no. 4, pp. 356-360, 2011.

[35] B. Hirshberg and A. Katz, "Cardiovascular outcome studies with novel antidiabetes agents: scientific and operational considerations," Diabetes Care, vol. 36, no. 2, pp. S253-S258, 2013. 


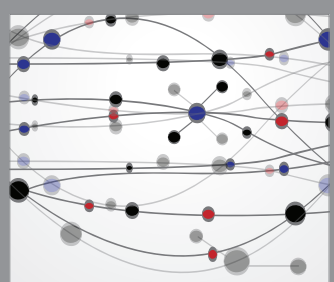

The Scientific World Journal
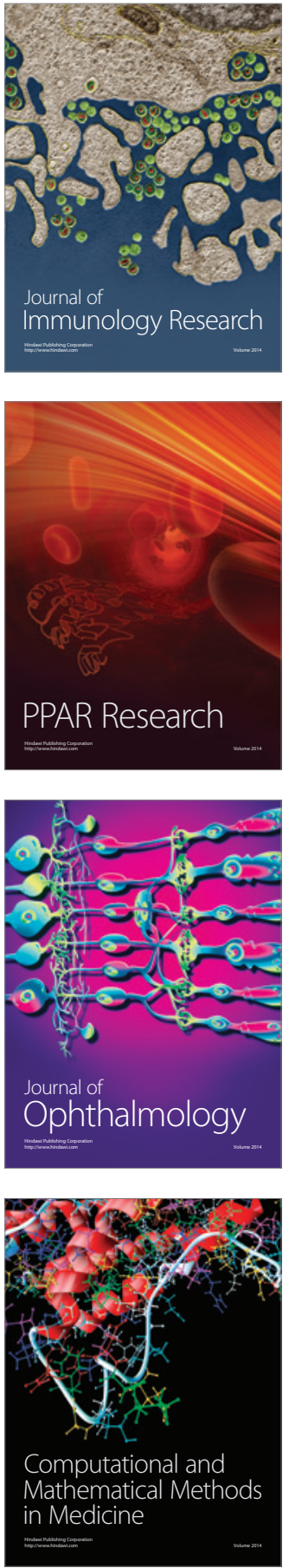

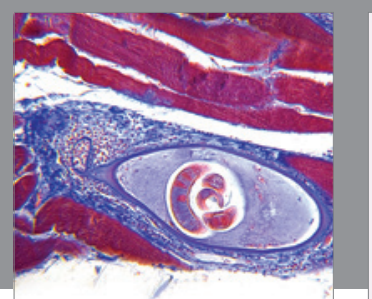

Gastroenterology Research and Practice

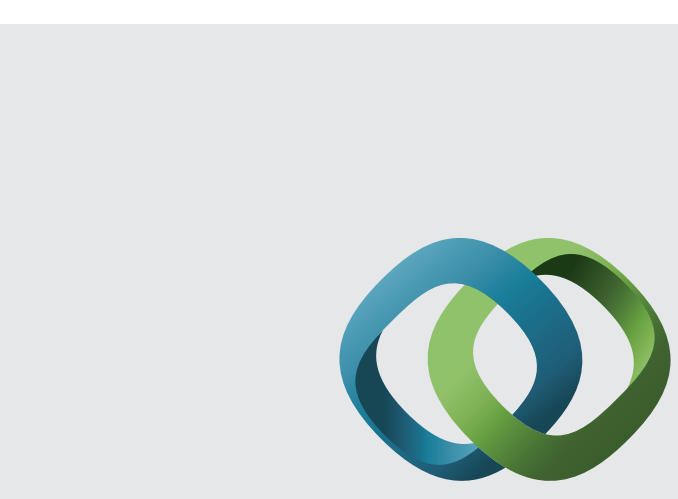

\section{Hindawi}

Submit your manuscripts at

http://www.hindawi.com
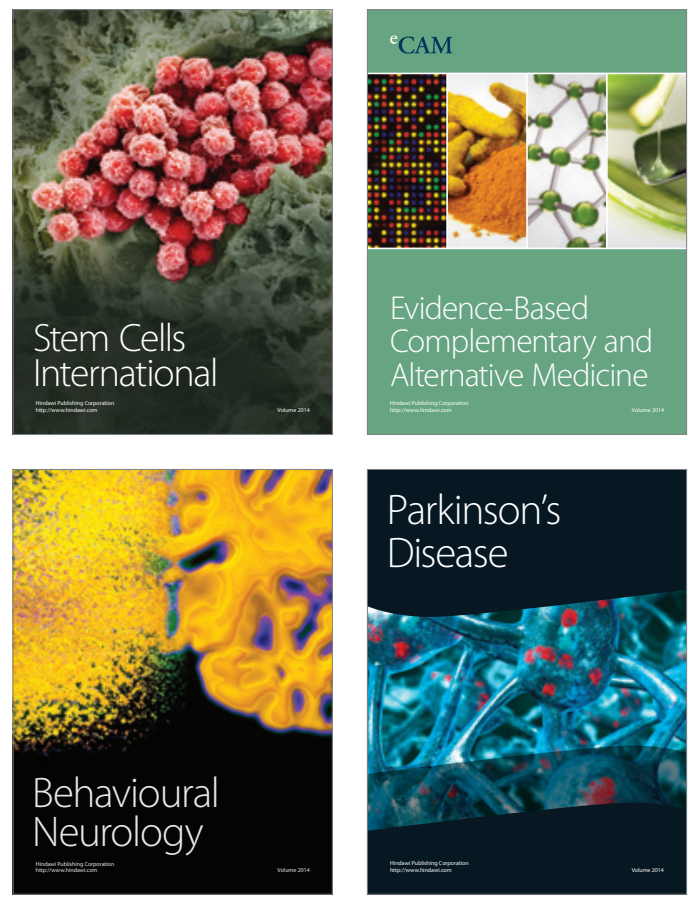
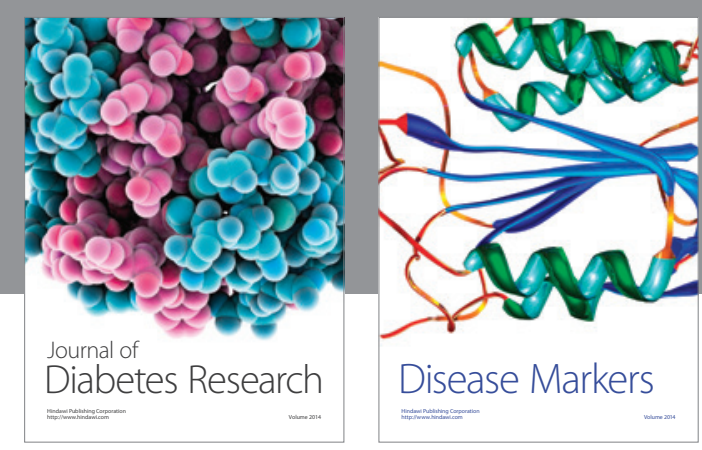

Disease Markers
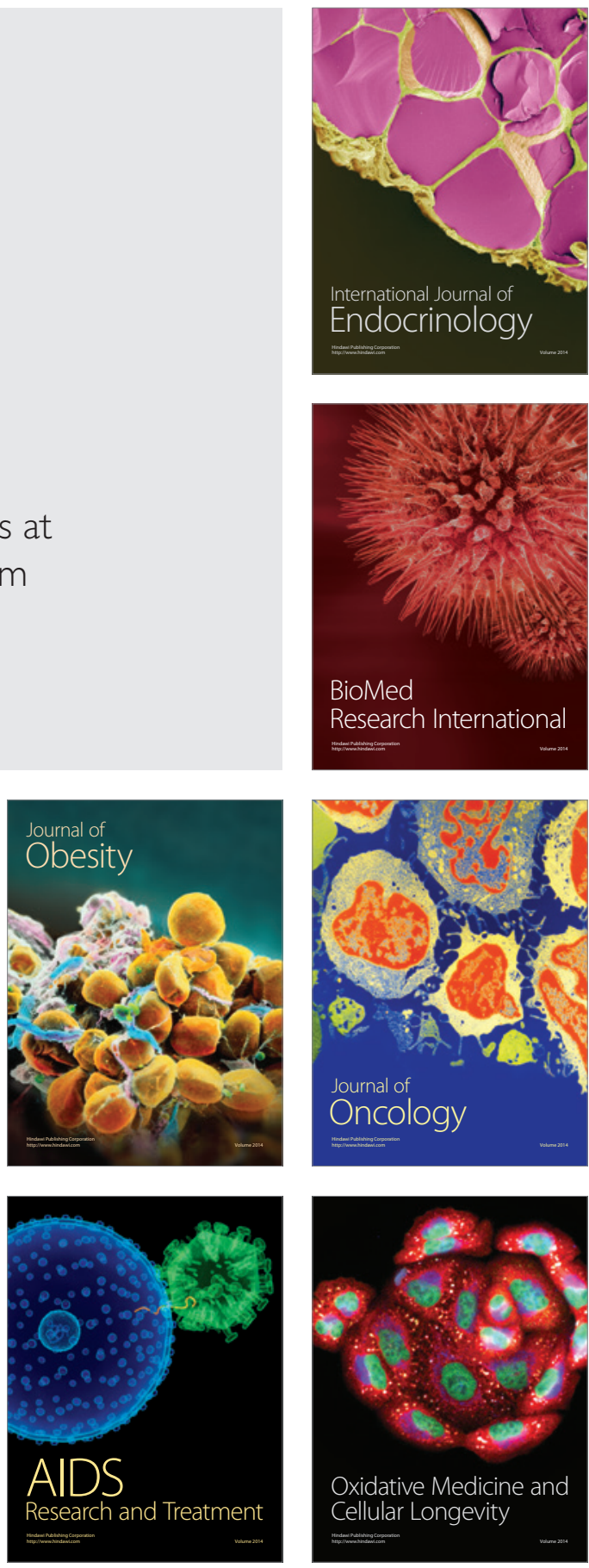